\title{
Incidence of capsular contracture in silicone versus saline cosmetic augmentation mammoplasty: A meta-analysis
}

\author{
Yasser El-Sheikh $M D^{1}$, Roberto Tutino $\mathrm{MD}^{2}$, Casey Knight $\mathrm{MD}^{1}$, Farough Farrokhyar $\mathrm{PhD}^{3}$, \\ Nicolas Hynes MSc MD FRCSC ${ }^{1}$
}

\begin{abstract}
Y El-Sheikh, R Tutino, C Knight, F Farrokhyar, N Hynes. Incidence of capsular contracture in silicone versus saline cosmetic augmentation mammoplasty: A meta-analysis. Can J Plast Surg
\end{abstract} 2008;16(4):211-215.

INTRODUCTION: Capsular contracture after augmentation mammoplasty occurs at a rate of $15 \%$ to $45 \%$. The purpose of the present study was to determine the effect of implant core type (silicone versus saline) on the rate of capsular contracture in augmentation mammoplasty.

METHODS: A systematic review was conducted through a search of three electronic databases. Two reviewers independently scanned titles yielded by the search and identified potentially relevant papers. Interreviewer variability and the scientific quality of the articles were assessed. Meta-analysis was performed.

RESULTS: Eighty-eight titles of potential relevance were selected from the 393 articles yielded by the search. Inter-rater agreement for selection of potentially relevant articles was $84 \%(\kappa=0.54)$. Four comparative studies were included in the analysis. Scientific quality scores of the included studies ranged from 5 of 14 to 9 of 14 . Three of the four studies reported a higher rate of capsular contracture in patients with silicone implants. A combined odds ratio calculated on two of the studies found a 2.25 -fold increased risk of capsular contracture in patients who received silicone implants. Eight series of patients who received cohesive gel silicone implants reported rates of capsular contracture from $0 \%$ to $13.6 \%$.

CONCLUSIONS: Higher rates of capsular contracture were found in patients who received silicone implants when compared with those who received saline implants. However, the scientific quality of the comparative studies to date on this subject is poor. Recent series evaluating cohesive gel implants report relatively low rates of capsular contracture. A randomized controlled trial comparing rates of capsular contracture in cohesive gel and saline implants is recommended.

Key Words: Capsular contracture; Meta-analysis; Saline; Silicone; Systematic review

$S_{\text {iit }}^{\text {il }}$ icone implants for augmentation mammoplasty were first introduced in 1962 (1,2). Since then, they have undergone many changes in terms of design and materials. There have been at least five generations of silicone implants to date, each using a different combination of core material and shell type (3). Each subsequent generation of silicone implants was introduced in an attempt to improve their aesthetic quality and feel, and to reduce their complication rates. Cohesive gel implants were introduced in 1993 and represent the latest generation of silicone breast implants on the market today (3).

Despite many improvements in breast implant design and surgical technique, capsular contracture continues to be a

\section{Incidence de la contracture capsulaire après mammoplastie d'augmentation par prothèse de silicone ou de solution saline : Méta-analyse}

\begin{abstract}
INTRODUCTION : Le taux de contracture capsulaire consécutive à la mammoplastie d'augmentation se situe entre $15 \%$ et $45 \%$. Le but de la présente étude était de déterminer l'effet du type de prothèse (silicone vs solution saline) sur le taux de contracture capsulaire consécutive à la mammoplastie d'augmentation.

MÉTHODES : Les auteurs ont procédé à une revue systématique de trois bases de données. Deux examinateurs ont chacun de leur côté fait un survol des titres générés par l'interrogation et ont sélectionné les articles pertinents. Après une évaluation de la variabilité interexaminateur et de la qualité scientifique des articles, les auteurs ont réalisé une méta-analyse des études rapportées.
\end{abstract}

RÉSULTATS : Les auteurs ont retenu 80 titres potentiellement pertinents parmi les 393 articles générés par l'interrogation. Pour ce qui est du choix des articles potentiellement pertinents, l'accord interexaminateur a été de $84 \%(\kappa=0,54)$. Quatre études comparatives ont été incluses dans l'analyse. Les scores de qualité scientifique des études incluses variaient de 5 sur 14 à 9 sur 14. Trois des quatre études faisaient état d'un taux de contracture capsulaire plus élevé chez les patientes qui avaient reçu des implants de silicone. Le calcul d'un rapport des cotes combiné de deux des études a révélé un risque 2,25 fois plus grand de contracture capsulaire chez les patientes qui avaient reçu des implants de silicone. Huit séries de patientes ayant reçu des prothèses de gel cohésif de silicone ont présenté des taux de contracture capsulaire allant de $0 \%$ à $13,6 \%$.

CONCLUSIONS : Des taux plus élevés de contracture capsulaire ont été observés chez les patientes ayant reçu des prothèses de silicone plutôt que des prothèses de solution saline. Toutefois, la qualité scientifique des études comparatives réalisées sur le sujet à ce jour laisse à désirer. De récentes séries évaluant les prothèses de gel cohésif de silicone révèlent des taux relativement faibles de contracture. Les auteurs recommandent la réalisation d'un essai randomisé et contrôlé comparant les taux de contracture capsulaire associés aux implants de gel cohésif de silicone et de solution saline.

significant problem. Reported rates of clinically significant capsular contracture are between $15 \%$ and $45 \%(2-5)$, with $92 \%$ of these occurring in the first year after surgery (6). A recent meta-analysis (6) found surface texturing to be protective against capsular contracture in patients with breast implants placed in the subglandular position. There has been no meta-analysis to date looking at the effect of breast implant core type on rates of capsular contracture.

In 1992, the United States Food and Drug Administration announced a moratorium on the use of silicone breast implants, citing their possible link to rheumatic diseases and breast cancer (1). Since then, evidence has amassed discrediting these claims (7-12) and on November 16, 2006, silicone

${ }^{1}$ Department of Surgery, Division of Plastic Surgery, McMaster University, Hamilton; ${ }^{2}$ Department of Surgery, Division of Plastic Surgery,

University of Toronto, Toronto; ${ }^{3}$ Department of Clinical Epidemiology and Biostatistics, McMaster University, Hamilton, Ontario

Correspondence: Dr Nicolas Hynes, 199 MacNab Street South, Hamilton, Ontario L8P 3C8. Telephone 905-645-5640, fax 905-645-5643,

e-mail nicolas.hynes1@sympatico.ca 
implants were reapproved for market distribution in Canada. Given that these devices are now more readily available to patients and surgeons, we performed a meta-analysis to determine:

- The effect of implant core type (silicone versus saline) on rates of capsular contracture in augmentation mammoplasty patients; and

- The reported rates of capsular contracture in augmentation mammoplasty patients who received cohesive gel implants.

Our hypothesis, based on clinical experience and an informal review of the literature, was that saline core type would be protective against capsular contracture.

\section{Literature search}

\section{METHODS}

A systematic review was conducted through a literature search of MEDLINE/PubMed, EMBASE and Cochrane electronic databases. Key terms were chosen in consultation with a librarian and were based on the existing index terms used in the three databases. In MEDLINE/PubMed, the key terms "breast implantation" or "breast implants" were combined with "mammoplasty" and "capsular contracture" or "contracture". Search limits included language (English only) and date published (1966 to 2006). In EMBASE, key terms "breast augmentation" or "breast endoprosthesis" were combined with "capsular contracture" or "contracture". Search limits included language (English only) and date published (1980 to 2006).

\section{Inclusion criteria}

Two reviewers (YE and CK) independently scanned the titles yielded by the above searches to identify potentially relevant papers. Inclusion criteria for titles of potential relevance were: mention of 'breast', 'implants', 'augmentation' or 'mammoplasty' with 'capsular contracture', 'silicone', 'saline' or 'complications' in the title; or any title too ambiguous to indicate the paper's relevance to the study questions. Because it was suspected that the studies yielded by the search would be heterogeneous in design, study design, participants, interventions or outcomes were not specified in the inclusion criteria, to capture all the published articles on capsular contracture in breast augmentation surgery.

Inter-reviewer variability for selection of titles of potential relevance was assessed using the kappa statistic. Any disagreement between reviewers regarding title selection was resolved through discussion and review of the abstract. A third reviewer (NH) was available to resolve any persistent disagreement if consensus could not be reached. The abstracts of articles chosen as potentially relevant were manually searched as well.

\section{Data abstraction}

All articles with titles of potential relevance were read in their entirety and from these, comparative studies looking at capsular contracture in silicone and saline implant augmentation mammoplasty were selected for data abstraction. Data collected from each article included publication date, sample size, follow-up period, age of patients, indication for surgery (cosmetic versus reconstructive), primary outcome measure and rates of capsular contracture.

Articles looking at capsular contracture in patients with cohesive silicone gel implants were included and analyzed separately.

\section{Scientific quality assessment}

Two reviewers (YE and RT) independently assessed scientific quality of included studies using a modified van Tulder scale (13). This 14-point scale, which includes questions on four domains (patient selection, interventions, outcome measures and statistics), is appropriate for assessment of comparative surgical trials.

\section{Heterogeneity analysis}

All comparative studies included in the analysis were assessed for clinical and statistical heterogeneity to determine whether quantitative pooling of data among studies would be possible and valid. Pooled odds ratios were only calculated in the case of low clinical and statistical heterogeneity.

\section{Search results}

\section{RESULTS}

The search strategy yielded 393 unique articles. Of these, 56 were judged by both reviewers to be titles of potential relevance. After discussion and abstract review, another 32 studies were chosen, giving a total of 88 titles of potential relevance. The inter-reviewer agreement was $84 \%(\kappa=0.54)$. All 88 titles were from the MEDLINE search. No titles were found in the EMBASE or Cochrane searches. From these, four comparative studies satisfied a priori criteria for inclusion in the data analysis. Eight retrospective case series looking at capsular contracture in patients with cohesive gel implants were also included (Figure 1).

\section{Scientific quality}

Scientific quality scores of the comparative studies ranged from 5 of 14 to 9 of 14 , using the modified van Tulder scale. The eight studies looking at cohesive gel implants were all retrospective case series, and therefore were of poor scientific quality.

\section{Data abstraction}

The comparative studies were published between 1979 and 2001. Sample sizes ranged from $n=79$ to $n=1343$. Only one study reported patient age, which was an average of 35 years. Follow-up times were reported in three studies $(2,4,5)$ and ranged between seven and 29 months. The indication for surgery in all studies was primary cosmetic augmentation mammoplasty. Two studies $(2,23)$ used the Baker classification (14) of capsular contracture as their primary outcome, with grades II to IV being considered clinically significant. One study (5) used the patients' subjective complaint of breast firmness as their primary outcome. Another study (4) used the patients' reports of palpable firmness as their primary outcome (Table 1).

The types of silicone and saline implants used within each study and between studies varied significantly. One study (23) did not report the manufacturers of the implants used. The remaining three studies $(2,3,5)$ used exclusively Heyer-Schulte saline implants. Regarding the silicone implants, one study (2) used exclusively Heyer-Schulte devices. The two other studies $(4,5)$ used implants produced by Heyer-Schulte, Dow Corning, McGhan, Surgitek and Cox-Uphoff, and some by an undisclosed manufacturer. Implant position was also variable, with two studies $(2,5)$ reporting on subglandular implants, one study (23) reporting on both subglandular and submuscular implants and the fourth study (4) not reporting implant position (Table 2).

\section{Heterogeneity analysis}

Regarding clinical heterogeneity, all four comparative studies looked at primary cosmetic augmentation mammoplasty patients. 


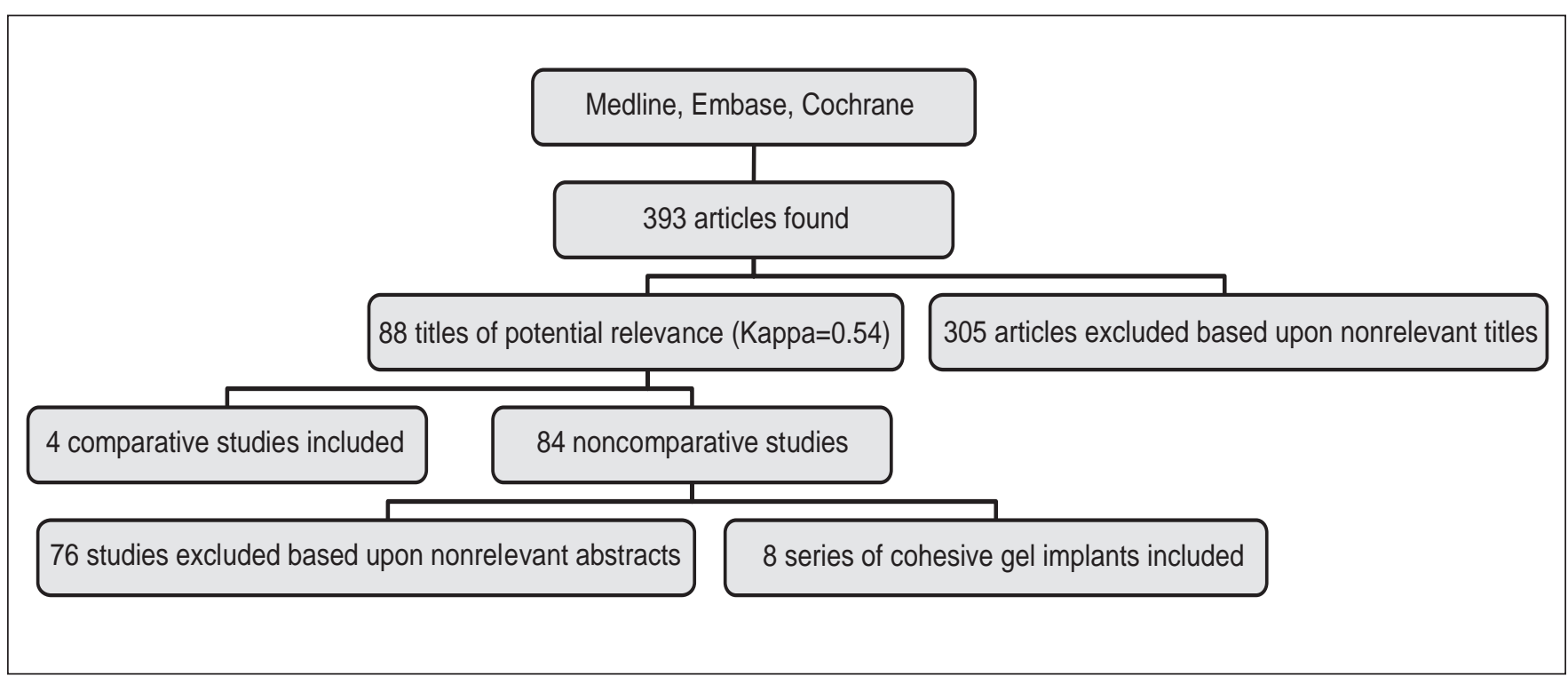

Figure 1) Article selection results

TABLE 1

Patient demographics and study design elements of comparative studies

\begin{tabular}{|c|c|c|c|}
\hline Reference & Patients & Follow-up & Outcome measure \\
\hline $\begin{array}{l}\text { McKinney and } \\
\text { Tresley, } 1983 \text { (5) }\end{array}$ & Cosmetic & $>12$ months & $\begin{array}{l}\text { Patient complaint of } \\
\text { subjective firmness }\end{array}$ \\
\hline Hetter, 1979 (4) & Cosmetic & 17-29 months & $\begin{array}{c}\text { Patient complaint of } \\
\text { palpable firmness }\end{array}$ \\
\hline $\begin{array}{l}\text { Cairns and De } \\
\text { Villiers, } 1980 \text { (2) }\end{array}$ & Cosmetic & $>7$ months & Baker II-IV contracture \\
\hline $\begin{array}{l}\text { Kjoller et al, } 2001 \\
\text { (23) }\end{array}$ & Cosmetic & Not reported & Baker II-IV contracture \\
\hline
\end{tabular}

TABLE 2

Implant manufacturer and position reported in comparative studies

\begin{tabular}{|c|c|c|c|}
\hline Reference & Silicone & Saline & Implant position \\
\hline $\begin{array}{l}\text { McKinney and } \\
\text { Tresley, } 1983 \\
\text { (5) }\end{array}$ & $\begin{array}{l}\text { Dow Corning or } \\
\text { Heyer-Schulte }\end{array}$ & Heyer-Shulte & Subglandular \\
\hline $\begin{array}{l}\text { Hetter, } 1979 \\
\text { (4) }\end{array}$ & $\begin{array}{l}\text { McGhan, Heyer- } \\
\text { Schulte, Dow } \\
\text { Corning, Surgitek, } \\
\text { Cox-Uphoff, } \\
\text { Unknown }\end{array}$ & $\begin{array}{l}\text { Hayer-Schulte } \\
\text { (Jenny } \\
\text { Prosthesis) }\end{array}$ & Not reported \\
\hline $\begin{array}{l}\text { Cairns and De } \\
\text { Villiers, } 1980 \\
\text { (2) }\end{array}$ & $\begin{array}{l}\text { Heyer-Schulte } \\
\text { (implants from } \\
\text { 1974-1978) }\end{array}$ & $\begin{array}{l}\text { Heyer-Schulte } \\
\text { (implants from } \\
\text { 1974-1978) }\end{array}$ & Subglandular \\
\hline $\begin{array}{c}\text { Kjoller et al, } \\
2001 \text { (23) }\end{array}$ & $\begin{array}{l}\text { Not reported } \\
\quad \text { (implants from } \\
\text { 1977-1997) }\end{array}$ & $\begin{array}{l}\text { Not reported } \\
\quad \text { (implants from } \\
\text { 1977-1997) }\end{array}$ & $\begin{array}{l}\text { Subglandular, } \\
\text { submuscular }\end{array}$ \\
\hline
\end{tabular}

However, the implant types used and their position was variable both between and within studies. The studies by Cairns and De Villiers (2) and Kjoller et al (23) both used the Baker classification of capsular contracture as their primary outcome measure (grades II to IV being defined as clinically significant). McKinney and Tresley (5) and Hetter (4) both used patient-perceived outcomes to measure capsular contracture.

Statistical heterogeneity was therefore calculated between studies that used similar primary outcome measures, to determine if pooled odds ratios could be calculated. There was low
TABLE 3

Rates of capsular contracture reported in comparative studies

\begin{tabular}{lcccc}
\hline Reference & Silicone $\left(\mathrm{n}_{1}\right)$ & $\begin{array}{c}\text { Contracture } \\
(\%)\end{array}$ & Saline $\left(\mathrm{n}_{2}\right)$ & $\begin{array}{c}\text { Contracture } \\
(\%)\end{array}$ \\
\hline $\begin{array}{l}\text { McKinney and } \\
\text { Tresley, 1983 }\end{array}$ & 111 & 36 & 58 & 24 \\
$(5)$ & & & & \\
Hetter, 1979 (4) & 107 & 64 & 58 & 40 \\
$\begin{array}{l}\text { Cairns and De } \\
\quad \text { Villiers, 1980 }\end{array}$ & 43 (implants) & 91 & 36 (implants) & 22 \\
$\quad(2)$ & & & & \\
Kjoller et al, & 823 (implants) & 9 & 18 (implants) & 44 \\
$2001(23)$ & & & & \\
\hline
\end{tabular}

statistical heterogeneity between the McKinney and Tresley (5) and Hetter (4) studies $(\mathrm{P}=0.3695)$ and high statistical heterogeneity between the Cairns and De Villiers (2) and Kjoller et al $(23)$ studies $(\mathrm{P}<0.0001)$. Individual results were therefore reported from all four studies and a pooled odds ratio was calculated using the McKinney and Tresley and Hetter data. The Cairns and De Villiers and Kjoller et al studies could not be pooled quantitatively because of high clinical and statistical heterogeneity.

Comparative study results

Three of the four comparative studies reported higher capsular contracture rates in patients with silicone implants compared with saline $(2,4,5)$ (Table 3$)$. The pooled odds ratio using data from the McKinney and Tresley and Hetter studies was 2.25 , indicating a greater than twofold increased risk of capsular contracture in patients who received silicone implants (Figure 2).

Cohesive gel series results

The cohesive gel series were published between 2001 and 2006 $(1,16-22)$. Sample sizes ranged from $n=14$ to $n=823$. Patient age was reported in six of these series, with averages ranging between 32 and 45 years. Follow-up times were reported in six series and ranged between 21 months and four years. Seven studies reported indications for surgery, with four series looking 


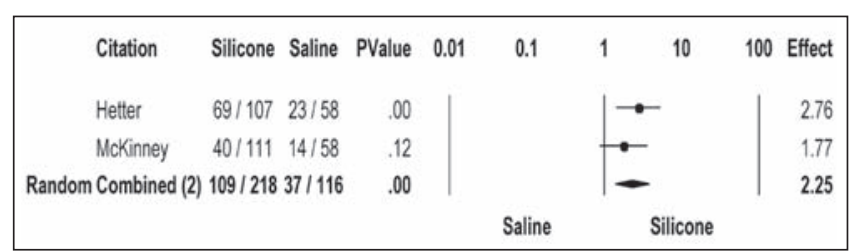

Figure 2) Individual and combined odds ratios for McKinney and Tresley (5) and Hetter (4) studies

at primary cosmetic augmentation mammoplasty patients and three series looking at both cosmetic and reconstructive patients. Seven of the eight case series reported the outcome measure used (Baker classification of capsular contracture). The capsular contracture rates reported in the cohesive gel series ranged between $0 \%$ and $13.6 \%$ (Table 4 ).

\section{DISCUSSION}

The results of the present systematic review and meta-analysis indicate that there were higher rates of capsular contracture in augmentation mammoplasty patients who received silicone implants when compared with those who received saline implants. The pooled odds ratio calculated using results from two comparable comparative studies was 2.25 , indicating a greater than twofold increased risk of capsular contracture in patients who received silicone implants.

There are a number of study limitations that need to be acknowledged at this time. Regarding internal study validity, the scientific quality of all the studies found in this review was poor, with average scores ranging from 5 of 14 to 9 of 14 . We must therefore be careful about interpreting these findings as definitive evidence. Furthermore, there was high variability in terms of silicone implant type, implant position and primary outcome measures used in the comparative studies to date. The McKinney and Tresley (5) and Hetter (4) studies were the most comparable of the four (ie, similar indication for surgery, similar primary outcome measures and low statistical heterogeneity) and were therefore combined quantitatively. Ideally, these two studies would also have used the same implant types inserted in the same position, to further justify pooling of their data.

Another difficulty that became apparent while conducting this study was that there is a lack of standardized reporting in the publications we reviewed. This made it difficult to compare and pool results across studies because the information we rely on to determine if study samples represent similar populations was not always available. In the future, it is our recommendation that authors adhere to published guidelines for reporting

\section{REFERENCES}

1. Heden P, Jernbeck J, Hober M. Breast augmentation with anatomical cohesive gel implants. Clin Plast Surg 2001;28:531-52.

2. Cairns TS, De Villiers W. Capsular contracture after breast augmentation - a comparison between gel and saline filled prostheses. S Afr Med J 1980;57:951-3.

3. Henriksen TF, Fryzek JP, Holmich LR. Surgical intervention and capsular contracture after breast augmentation. Ann Plast Surg 2005;54:343-51.

4. Hetter GP. Satisfaction and dissatisfactions of patients with augmentation mammaplasty. Plast Reconstr Surg 1979;64:151-5.

5. McKinney P, Tresley G. Long term comparison of patients with gel and saline mammary implants. Plast Reconstr Surg $1983 ; 72: 27-9$

6. Barnsley G, Sigurdson L, Barnsley S. Textured surface breast implants in the prevention of capsular contracture among breast
TABLE 4

Capsular contracture rates reported in cohesive gel series

\begin{tabular}{lcc}
\hline Reference & $\begin{array}{c}\text { Number of } \\
\text { implants (n) }\end{array}$ & $\begin{array}{c}\text { Capsular } \\
\text { contracture (\%) }\end{array}$ \\
\hline Bogetti et al, 2000 (16) & 14 & 0 \\
Heden et al, 2001 (1) & 823 & 5 \\
Kulmala et al, 2004 (17) & 100 & 8 \\
Fruhstorfer et al, 2004 (18) & 10 & 0 \\
Brown et al, 2005 (19) & 118 & 1.7 \\
Seify et al, 2005 (20) & 44 & 13.6 \\
Bengtson et al, 2007 (21) & 455 & 13.2 \\
Cunningham, 2007 (22) & 551 & 8.1 \\
\hline
\end{tabular}

of comparative studies (15). This will allow subsequent investigators to critically appraise published studies and perform accurate meta-analyses.

In terms of external study validity, three of the four comparative studies included in our analysis were published between 1979 and 1983, which would indicate that they were evaluating older generations of silicone implants. These implants have been replaced in today's market by the newer cohesive gel implants. Unfortunately, we found no studies comparing saline implants with cohesive gel implants, so to improve the external validity of our review, we included all the published case series that looked at capsular contracture rates in patients who received cohesive gel implants. The capsular contracture rates reported in these series ranged between $0 \%$ and $13.6 \%$, which is lower than the rates found in the comparative studies reviewed and in published historical controls to date $(1,16-22)$.

Cohesive gel implants are being used frequently in cosmetic augmentation mammoplasty patients today. Most surgeons agree that these latest generation silicone implants give a better cosmetic result with less rippling and a more natural feel than saline implants. Given that silicone implants have now received government approval for free market use in Canada, their prevalence is likely to increase. We therefore recommend that a randomized controlled trial be performed comparing capsular contracture rates in cohesive gel and saline implants, to give us a definitive and more relevant answer to our study question. Until such a study is completed, the present metaanalysis represents the best evidence to date on rates of capsular contracture in silicone versus saline implant augmentation mammoplasty.

CONFLICTS OF INTEREST: None to declare.

augmentation patients: A meta-analysis of randomized controlled trials. Plast Reconstr Surg 2006;117:2182-90.

7. Berkel H, Birdsell DC, Jenkins H. Breast augmentation - a risk factor for breast cancer? N Engl J Med 1992;326:1649-53.

8. Deapen DM, Brody GS. Augmentation mammoplasty and breast cancer: A 5 year update of the Los Angeles study. Plast Reconstr Surg 1992;89:660-5.

9. Deapen DM, Pike MC, Casagrande JT, et al. The relationship between breast cancer and augmentation mammoplasty: An epidemiologic study. Plast Reconstr Surg 1986;77:361-8.

10. Perkins LL, Clark BD, Klein PJ, et al. A meta-analysis of breast implants and connective tissue disease. Ann Plast Surg 1995;35:561-70.

11. Duffy MJ, Woods JE. Health risks of failed silicone gel breast implants: A 30 year clinical experience. Plast Reconstr Surg 1994;94:295-9. 
12. Gabriel SE, O'Fallon WM, Kurland LT, et al. Risk of connective tissue diseases and other disorders after breast implantation. N Engl J Med 1994:330:1697-702.

13. Van Tulder MW, Assendelft WJ, Koes BW. Method guidelines for systematic reviews in the Cochrane Collaboration Back Review Group for Spinal Disorders. Spine 1997;22:2323-30.

14. Little G, Baker JL Jr. Results of closed compression capsulectomy for treatment of contracted breast implant capsules. Plast Reconstr Surg 1980;65:30-3.

15. Stroup DF, Berlin JA, Morton SC, et al. Meta-analysis of observational studies in epidemiology: A proposal for reporting. JAMA 2000;283:2008-12.

16. Bogetti P, Boltri M, Balocco P, et al. Augmentation mammaplasty with a new cohesive gel prosthesis. Aesth Plast Surg 2000;24:440-4.

17. Kulmala I, McLaughlin JK, Pakkanen M, et al. Local complications after cosmetic breast implant surgery in Finland. Ann Plast Surg 2004;53:413-9.

18. Fruhstorfer BH, Hodgson EL, Malata C. Early experience with an anatomical soft cohesive silicone gel prosthesis in cosmetic and reconstructive breast implant surgery. Ann Plast Surg 2004;53:536-42.
19. Brown MH, Shenker R, Silver SA. Cohesive silicone gel breast implants in aesthetic and reconstructive breast surgery. Plast Reconstr Surg 2005;116:768-79.

20. Seify H, Sullivan K, Hester TR. Preliminary (3 years) experience with smooth wall silicon gel implants for primary breast augmentation. Ann Plast Surg 2005;54:231-5.

21. Bengtson BP, Van Natta BW, Murphy DK, et al. Style 410 highly cohesive silicone breast implant core study results at 3 years. Plast Reconstr Surg 2007;120:40s-8s.

22. Cunningham B. The Mentor Core Study on Silicone MemoryGel Breast Implants. Plast Reconstr Surg 2007;120(Suppl 1):30S-2S.

23. Kjoller K, Lisbet HR, Jacobsen PH, et al. Capsular contracture after cosmetic breast implant surgery in Denmark. Ann Plast Surg 2001;47:359-66.

24. Bhandari M, Devereaux PJ, Montori V, et al. User's guide to the surgical literature: How to use a systematic literature review and meta-analysis. Can J Surg 2004:47:60-7.

25. Brody GS. On the safety of breast implants. Plast Reconstr Surg 1997;100:1314-21.

26. Cochrane Database. The Cochrane Collaboration's open learning material for reviewers. <www.cochrane.org/> (Version current at October 3, 2008). 